NBER WORKING PAPER SERIES

\title{
CHOOSING AGENTS AND MONITORING CONSUMPTION: A NOTE ON WEALTH AS A CORRUPTION-CONTROLLING DEVICE
}

\author{
Rafael Di Tella \\ Federico Weinschelbaum \\ Working Paper 13163 \\ http://www.nber.org/papers/w13163
NATIONAL BUREAU OF ECONOMIC RESEARCH
1050 Massachusetts Avenue
Cambridge, MA 02138 \\ June 2007
}

We thank Christopher Bliss, Ernesto Dal Bo, Robert MacCulloch and participants at several seminars for helpful discussions and suggestions. An earlier version of this paper was circulated under the title "To Catch a Thief: Wealth as a Corruption Controlling Device". The views expressed herein are those of the author(s) and do not necessarily reflect the views of the National Bureau of Economic Research.

(C) 2007 by Rafael Di Tella and Federico Weinschelbaum. All rights reserved. Short sections of text, not to exceed two paragraphs, may be quoted without explicit permission provided that full credit, including $(\odot$ notice, is given to the source. 
Choosing Agents and Monitoring Consumption: A Note on Wealth as a Corruption-Controlling Device

Rafael Di Tella and Federico Weinschelbaum

NBER Working Paper No. 13163

June 2007

JEL No. D82,K42

\begin{abstract}
$\underline{\text { ABSTRACT }}$
There are a large number of cases where corruption has been discovered investigating levels of consumption that appear to be hard to justify. Yet, in the standard moral hazard model withholding of effort by the agent is not observable to the principal. We argue that this assumption has to be revised in applications that study corruption. The informativeness of an agent's level of consumption depends on his legal income and initial level of wealth, as conspicuous consumption by wealthy agents leads to little updating of the principal's belief about their honesty. This introduces a tendency to prefer poor agents as they are easier to monitor. More generally, we describe the basic problem of choosing agents and monitoring consumption with the aim of reducing corruption, and discuss features of the practical applications. We show that when there is consumption monitoring and wealth is observed, the effect of higher wealth on equilibrium bribes is ambiguous (and that the political class will exhibit lower variance in consumption than the general population). In settings where formal contracts matter, we show that monitoring consumption introduces a tendency towards low powered incentives (and more generally low wages). We also discuss the role of ability, the tax system, and the way to derive a measure of the value of illegal funds for the agent.
\end{abstract}

\author{
Rafael Di Tella \\ Harvard Business School \\ Soldiers Field Rd \\ Boston, MA 02163 \\ and NBER \\ rditella@hbs.edu \\ Federico Weinschelbaum \\ Universidad de San Andres \\ fweinsch@udesa.edu.ar
}




\section{Introduction}

Castrated slaves, called eunuchs, were employed by Sultans to guard their harems. This solution to a particularly distressing principal-agent problem is one instance of a general strategy that can be called "choosing agents". In this strategy, the principal selects an agent, on whom he is about to delegate a task, based on an observable characteristic. In the standard agency model it is clear that the agent's degree of risk aversion can be costly to the principal. Perhaps because of the difficulty in observing risk aversion, few economists have emphasized the potential benefits of using particular types of agents. Schelling (1960), for example, discusses the use of agents with a low personal cost of conflict and mentions the strategic advantages of delegating authority "to a military commander of known motivation". A subsequent paper by Vickers (1985) emphasizes the potential value of hiring a manager that is committed to maximize the company's sales instead of profits. Similarly, Rogoff (1985) analyses the benefits of delegating the conduct of monetary policy to a conservative central banker in a setting where there is time inconsistency, while Rotemberg and Saloner (2000) study how hiring a manager biased towards pursuing certain type of projects (a "visionary") helps employees exert effort on innovative tasks. In all these examples there is a commitment benefit of choosing agents with particular preferences. In this paper we focus on the contractual benefits of choosing certain agents out of a population with similar preferences. The example of the eunuch illustrates an extreme case whereby selecting some agent eliminates the principal agent problem altogether. ${ }^{2}$ In general, the amount of rents left to the agent and/or the efficiency costs of the optimal incentive scheme will depend on the agent's observable characteristics.

We are particularly concerned with applications to corruption. The academic literature on corruption has discussed the effects of higher income on the behavior of agents that work in positions where there are opportunities to take bribes. This is the theme, for example, of the early paper by Becker and Stigler (1974) and the subsequent literature on efficiency wages. ${ }^{3}$

\footnotetext{
2 Note that even though Sultans in the Ottoman Empire could choose different types of eunuchs, those preferred for harem service were typically both black and Sandali (i.e., their genitalia were entirely amputated). ${ }^{3}$ See the income satiation model of Rasmusen (1992) and the model with different wage regimes of Besley and McLaren (1993). Both present discussions of corruption in an efficiency wage setting whereas Mookherjee and Png (1995) present a model of contingent rewards. There is also a large policy literature discussing how paying
} 
The idea is appealing because it can be related to the standard economic intuition of diminishing marginal utility. There are a number of examples of very wealthy individuals that have been elected in countries where corruption is an important political preoccupation. One the famous cases is that of Silvio Berlusconi, who was elected prime minister in Italy of 1994, in the aftermath of tangentopoli, the corruption scandals that shocked the Italian political establishment in the early nineties. The owner of a vast business empire, Berlusconi's acknowledged net annual earnings at the time of $U \$ 13.5$ million.

A second effect of wealth is evident in a large number of corruption cases, however. It is illustrated by the actions of the leaders of the popular uprising against President Ferdinand Marcos of the Philippines in 1986. After finding a number of luxury items at the presidential palace, including 2,300 pairs of shoes in First Lady Imelda Marcos' closet, they decided to protect and exhibit them, together with all of the contents as evidence of corruption on a grand-scale by the Marcos'. They reasoned that, since Marcos was not a wealthy man before entering politics, these items where probably acquired with dishonest income. ${ }^{4}$ Put differently, finding 2,300 pairs of shoes in Mrs Berlusconi's closet, would make her an eccentric rather than a crook. Interestingly, this is the logic used in the overwhelming majority of the cases where high-level corruption has been detected and punished. As part of a mild campaign against corruption in the early 1980's, the Mexican government charged (in absentia) the former chief of police of Mexico City with fraud. One of the reasons for the charges was his high standard of living. Apparently he was able to keep 15 racehorses and 19 vintage cars in his home. He also had 1,200 servants and had a second home modeled (in marble) on the Parthenon, all whilst on a $\mathrm{U} \$ 1,000$ monthly salary. ${ }^{5}$ The biggest spy scandal in the CIA's history occurred when counter espionage agents inquired how one of their top agents, Aldrich Ames, was able to afford a Ferrari. In the end, Ames' luxurious lifestyle prompted an investigation that uncovered the sale of secrets to the Soviet Union on the largest scale ever. Amongst these secrets was a list of CIA agents that were subsequently

higher wages can reduce corruption (e.g., World Bank (1997)). The approach is also a favorite with the press. For example, wage increases are a part of the effort to reduce corruption in the Mexican federal police. See "Reforming Mexico's police", The Economist, December 11, 1999.

${ }^{4}$ Ex-President Marcos, however, has denounced claims that he was worth more than U\$10bn (based on papers found at the palace) as politically motivated fabrications. He has officially declared assets for only U\$2bn. See The Times, June 12, 1986.

${ }^{5}$ Reported in The Economist, April 7, 1984. 
killed by the Soviets. ${ }^{6}$ According to Judge Gherardo Colombo from Milan, a former prosecutor in the "mani pulite" process, the value of monitoring the assets and lifestyles of public officials is one of the key lessons of the Italian experience. A paper summarizing the main practical issues (Colombo, 1997) goes further and argues that this is the only approach with some chance of success. ${ }^{7}$ One requirement for this effect to be operational is that the principal has some sense of what the agent's initial level of wealth is, either because we are dealing with a known political figure, or because there is access to prior tax payments or because there is a declaration of wealth prior to entering office and strategic exaggeration of personal wealth is too expensive (for political or tax reasons).

These arguments can be put in terms of the traditional moral hazard model. It suggests that applying it to study corruption requires more than a mere re-labeling of effort for bribes because withholding effort is unobservable while bribe consumption may be observable in some type of agents (the poor or those on very low wages). ${ }^{8} \mathrm{~A}$ direct implication is that there may be other quasi-observable characteristics of the agent that may facilitate this transmission of information besides their income, such as the agent's rate of discount. We conjecture that agent's with children, or with sick relatives may be easier to monitor, as they would have a higher tendency to consume education and health care services. Although all our examples come from corruption settings, it is possible that there are more general benefits from using observable characteristics to help reduce informational costs. As an example from industrial organization, consider the case of a firm that prefers to collude with

\footnotetext{
${ }^{6}$ Reported in the front page of The Times, December 29, 1994. For another application, see the minutes of the Meeting of the Federal Open Market Committee December 21, 1999. In it there is a discussion on some "missing" funds. After no explanation can be produced, the following exchange takes place:

CHAIRMAN GREENSPAN. Is there any evidence of a surprising rise in standards of living of key people involved?

MR. FISHER. No, there is not.

CHAIRMAN GREENSPAN. Has somebody looked?

MR. FISHER. Yes, we have looked into that. Many of the staff people are still at the Bank, though others are not. But we have found nothing of that nature. (We thank Ernesto Dal Bo for suggesting this example).

7 The secret nature of corrupt agreements, the fact the victims (taxpayers) are dispersed and there are incentives for free riding in monitoring corruption, the fact that penalties are stipulated to both those receiving bribes and those giving them, all conspire to make corruption a crime with extremely low rates of indictments.

8 Prendergast (2000) emphasizes a number of dimensions in which corruption does not fit well with the traditional hidden action agency model, including the difficulty of finding metrics on which to write anticorruption contracts. He emphasizes monitoring and investigations (as an alternative to writing incentive contracts) and the behavioral responses of the agent. On the combination of monitoring and investigations in the enforcement of law, see Mookherjee and Png (1992). See also Laffont and N'Guessan (1999) for a principal
} 
a small rather than a large rival because deviations from an agreement by a small firm are easier to observe (in some markets). 'As a potential application in public economics, consider the standard problem of trying to figure out the wealth/income of an individual for tax purposes. In fact, it is not uncommon in practice for tax authorities to monitor consumption in order to make comparisons with sworn fiscal declarations in an inference process that is very much related to the one we discuss in this paper. ${ }^{10}$ We think that our main point is, broadly, an extension of the informativeness principle (see Holmstrom (1979) and Shavell (1979)).

In the next section we describe the general problem and a measure of the gain from choosing agents and monitoring consumption to lay down the basic ideas. Given that in practice high-level politicians typically are bound by informal contracts, whereas lower level bureaucrats are motivated through formal incentive schemes, we separate the channels through which choosing agents and monitoring consumption matters. First, in the absence of a formal contract, monitoring consumption will still lead some type of agents to behave better than others. Second, writing a formal incentive contract may be cheaper for some type of agents. In section III we study informal contracts and show that under consumption monitoring we should not expect to always have lower corruption levels with richer politicians. We also analyze two extensions: the role of ability and the role of the tax system. In section IV we develop the case of formal contracts and show that the observability of consumption leads to low powered incentive contracts (there is less separation between the wages in the good and in the bad state). This is an argument against paying high wages to deter corruption. The main point of the paper naturally leads to a distinction (in terms of value to the agent) between money earned legally and money earned illegally, something that is assumed in many principal agent models. ${ }^{11}$

agent model applied to corruption. Gibbons and Waldman (1998) and Prendergast (1999) provide surveys of the agency literature.

9 We thank Hugo Hopenhayn for suggesting this example.

${ }^{10}$ In a recent example, the tax authority in Argentina monitored the identity of those purchasing luxury items, such as trips to ski resorts, and those consuming relatively expensive items that are necessities, such as plasma TV in the weeks prior to the 2006 Soccer World Cup and assistance to motels ("telos"). They then crossedchecked these identities with a list of fiscal debtors (see Candelaresi, 2006). 


\section{The Basic Problem of Choosing Agents and Monitoring Consumption}

\section{II.a. Basic Problem}

Assume that a principal wishes to hire an agent to do some task. The agent's original observable characteristic is $t_{i}^{0}$. The resulting observable characteristic of the agent after the implementation of payment scheme $r$ by the principal is $t_{i}\left(t_{i}^{0}, r\right)$. The principal chooses a payment scheme $r^{*}$ and an agent with original characteristic $t_{i}^{0 *}$ such that

$t_{i}^{0 *}, r^{*} \in A r g \max U_{p}\left(r, a^{*}\left(t_{i}^{0}, r\right)\right) \quad$ where $\quad a^{*}\left(t_{i}^{0}, r\right) \in \operatorname{Arg} \max U_{a}\left(r, a, t_{i}\left(t_{i}^{0}, r\right)\right)$

The principal's utility, $U_{p}($.$) , depends on the payment scheme and the agent's optimal$ action, $a^{*}$. And the agent's utility $U_{a}($.$) depends on the payment scheme, the agent's action$ and the resulting characteristic. A way to solve this problem, in the spirit of Grossman and Hart (1993), is to find the optimal payment scheme for each type and then choose the optimal type. Guided by the empirical applications which involve cases of high level (political) corruption as well as low-level (bureaucratic) corruption, we distinguish two channels through which the principal benefits from using observable characteristics and monitoring consumption. First, even in the absence of a formal contract, some types of agents will be more inclined to choose the actions desired by the principal. Second, some types of agents will be cheaper to motivate through a formal incentive contract.

To illustrate the first channel, we look for the optimal characteristic assuming that the principal cannot choose the formal payment scheme. In this case the solution is such that

$$
t_{i}^{0 *} \in A \operatorname{Arg} \max U_{p}\left(a^{*}\left(t_{i}^{0}\right)\right) \quad \text { where } \quad a^{*}\left(t_{i}^{0}\right) \in \operatorname{Arg} \max U_{a}\left(a, t_{i}^{0}\right)
$$

The principal's utility depends on the agent's action, while the agent's utility depends on the action and the original characteristic. The lack of formal contracts is common in high level

\footnotetext{
${ }^{11}$ See, for example, transaction costs in the agency models of regulatory capture (see, chapter 11 of Laffont and Tirole (1993) or the "moral costs" of taking bribes assumed often in the analysis of corruption since Rose-
} 
political settings, where corruption is often a preoccupation. ${ }^{12}$

To illustrate the second channel, we develop an example with homogeneous agents (same original characteristic) where the principal sets a formal contract. The focus is on the effect of the payment scheme on the resulting characteristic and how easy it will be to observe consumption. The solution is given by

$$
r^{*} \in \operatorname{Arg} \max U_{p}\left(r, a^{*}\left(t_{i}, r\right)\right) \quad \text { where } \quad a^{*}\left(t_{i}, r\right) \in \operatorname{Arg} \max U_{a}\left(r, a, t_{i}\right)
$$

The utility of the principal depends on the payment scheme and the agent's action. The utility of the agent depends on the contract and on the resulting characteristic. ${ }^{13}$

\section{II.b. Measure of the Gain from Choosing Agents and Monitoring Consumption}

In the general case the gains from choosing agents and monitoring consumption to the principal is

$$
M(0)=U_{p}\left(r^{*}\left(t_{i}^{0^{*}}\right), a^{*}\left(t_{i}^{0^{*}}, r^{*}\right)\right)-\int U_{p}\left(r^{a v}, a^{*}\left(t_{i}^{0}, r^{a v}\right)\right) d G\left(t_{i}^{0}\right)
$$

where $r^{a v}$ is the payment scheme that maximizes principal's utility given that it cannot be made contingent on type, and where $G\left(t_{i}^{0}\right)$ is the cumulative distribution function of types.

In the case where incentive contracts are not used (or are not tailored to each characteristic), the gain from choosing agents is

\footnotetext{
Ackerman (1975).

12 Note that in this case, there are no benefits originating in the fact that the principal can write a different (cheaper) contract for some type of agents, but rather from the fact that some agents are more likely to take a desired action. This description includes the case of agents who take actions due to the informal incentives they face and cases of agents whose preferences make them select actions that have commitment value (as with Rogoff's conservative central banker; for a study of contracts for central bankers, see Walsh, 1995 ).

${ }^{13}$ In our example, the benefits originate in the fact that a contract that takes into account a (given) characteristic and monitors consumption is cheaper for the principal. Different types of agent may be associated with differences in benefits, but the two channels are conceptually different. Formal contracts to deter corruption are common in bureaucracies, which are often characterized by the use of low powered incentive schemes (e.g., Tirole, 1994). And raising wages for bureaucrats is one of the most popular policy proposals to fight corruption.
} 
$M(1)=U_{p}\left(a^{*}\left(t_{i}^{0^{*}}\right)\right)-\int U_{p}\left(a^{*}\left(t_{i}^{0}\right)\right) d G\left(t_{i}^{0}\right)$

In the case where incentive contracts are tailored to the characteristics of the agent, a measure of the gain has two components. First, we have the gain from having a contract that fits the characteristic, even though the latter may not be the optimal one. This is given by

$$
M(2 a)=\int U_{p}\left(r^{*}\left(t_{i}^{0}\right), a^{*}\left(t_{i}^{0}, r^{*}\right)\right) d G\left(t_{i}^{0}\right)-\int U_{p}\left(r^{a v}\left(t_{i}^{0}\right), a^{*}\left(t_{i}^{0}, r^{a v}\right)\right) d G\left(t_{i}^{0}\right)
$$

Second, we have the gain from choosing the optimal characteristic.

$$
M(2 b)=U_{p}\left(r^{*}\left(t_{i}^{0^{*}}\right), a^{*}\left(t_{i}^{0^{*}}, r^{*}\right)\right)-\int U_{p}\left(r^{*}\left(t_{i}^{0}\right), a^{*}\left(t_{i}^{0}, r^{*}\right)\right) d G\left(t_{i}^{0}\right)
$$

Note that the gain in the general case, $M(0)$, can be quite large. Consider the standard problem of inducing an agent to exert effort in a task. Now allow for the possibility that agents differ in their skin pigmentation and that the only way to enjoy leisure is to spend time under the sun. In this case white agents are to be preferred to black agents, as white agents would exhibit sunburns if they were to withhold effort on the job, whereas black agents would exhibit no change in color. In this extreme example, the gain from choosing agents and monitoring consumption is $M(0)$. This is so because using a black agent takes us to the traditional principal agent model (with no information from observing consumption) and using a white agent takes us to a world where there are no principal agent problems. ${ }^{14}$

\section{No Contract, Choice of Agent}

In this section we consider the possibility of corruption in a setting where formal contracts cannot be written (by assumption), so this is an example of only choosing the agent's

\footnotetext{
14 More generally, when agents find it very costly to have no leisure at all, the optimal contract will include some leisure (besides a monetary payment). Interestingly, it will differ between the two types with white agents having relatively less time under the sun than black agents. The reason is that allowing white agents to spend
} 
characteristics, as explained in section II. The setup we consider has the advantage of being applicable to cases of corruption by high level officials and politicians, an area where there has been comparatively little research done. The only thing the public can do is to monitor the agent's consumption patterns, which are affected both by the bribes he takes and by the random changes to his wealth.

Consider an agent that is paid a fixed wage (normalized to zero) who has the opportunity to choose the amount of bribes $b$ to take. For concreteness, consider the case of a high level, elected politician in charge of privatizing a state enterprise that can under-invoice the sale without leaving any proof of wrongdoing. ${ }^{15}$

Assume the agent has a stock of wealth $t$, that produces a flow of honest income freely available for consumption, $v$. While wealth is verifiable, the amount $v$ is not observable to the public. A number of factors affect the size of the income realization $v$, including the returns to his legitimate investments and the amount of gifts the agent may receive like inheritance. After observing the return to his wealth $v$, the agent decides to take bribes in the amount $b$, for a total amount of income available of $v+b$. This is fully spent on consumption, $\mathrm{Z}$, as allowing for savings somewhat complicates the analysis without adding insight. Thus, consumption by the politician is

$z=v+b$

A standard way to think of $z$ is as consumption on luxury goods, such as spending on fancy cars or golden watches. However, successful cases of corruption detection, suggest including

time under the sun is more "expensive" since it would reduce the information that is transmitted to the principal when the agent withholds effort.

15 We do not model the source of the agent's power because we do not need so much detail to lay down the basic ideas. All we need is a situation where the politician can take bribes, and that he has complete legal discretion to do so. In other words, the politician runs no risk of detection or of ever receiving any form of legal punishments. Although admittedly extreme, the assumption provides a first approximation given the extraordinary low rate of detection of (perceived) corruption in practice. The following simple game (keeper of the treasure) illustrates. A guard is in charge of protecting the kingdom's treasure from some thieves. After these leave with their loot, the guard confronts the king and reports how much was stolen. The king can only observe the guard's standard of living before and after the raid, and reward the guard with honors, etc. Note that we are not allowing punishment to depend on wealth. This is natural if all punishment is in the form of utility, but for pecuniary punishments it is clearly easier to punish the wealthy. Modifying the model in this way does not alter the main results. 
goods on which consumption cannot be postponed. Indeed, as mentioned above, one of the lessons of the mani pulite investigations is that the usefulness of monitoring spending depends on the discount rate of consumption on the particular activity. Examples of areas with high discount rate include the education of children (particularly in countries where there is a large quality gap between private and free public schools) or spending on medical care (see Colombo, 1997). This reduces the possibility of having the agent shifting consumption across time. Although we assume that there is no (verifiable) trace of the agent's corrupt activities, we do assume the agent's consumption of luxuries is observable (presumably, that is the point with luxury goods). When the public observes these displays of wealth, it doesn't know if the agent was lucky or if he took bribes. ${ }^{16}$ Thus, the state of the world where the agent takes bribes and inherits nothing is observationally equivalent for the public to the state where the agent takes no bribes and receives a shock of legal income (e.g., an inheritance).

We assume that the variable $v$, the return to wealth, is distributed with a certain distribution function; that this is common knowledge; and that this induces a distribution function over $z$ that we denote with $F(z)$. Call the associated density function $f(z)$. The agent's objective function is

$I=U(z)-F(t, z) m$

The function $U($.$) is the agent's utility function and we assume it satisfies standard Inada$ conditions, and no restrictions on $F($.$) . The second term represents punishment for$ suspicions of corruption. When the public observes the politician's level of consumption, it calculates the probability that such a level was generated with zero bribes. The agent is punished by the public with reductions to their moral prestige (in units of utility) in the amount $m$. A simple interpretation is that $F($.$) is the probability of dishonesty and m$ is the personal cost of the public's lack of trust, possibly expressed as the number of votes.

\footnotetext{
16 When asked about his 2,300 pairs of shoes, Marcos can always claim that he inherited money from a relative or invested his salary wisely.
} 
The timeline is as follows.

$\begin{gathered}\text { choose agent with } \\ \text { wealth } t\end{gathered}$
inheritance $\mathrm{v}$ $\begin{gathered}\text { agent chooses bribes } \mathrm{b} \\ \text { public observes consumption } z\end{gathered}$

First the public chooses a politician from a pool of agents that can only be distinguished by their wealth. Second, the random realization to wealth is revealed to the politician. Third, the politician chooses a level of bribes and total consumption of luxuries is revealed to the public. ${ }^{17}$ Lastly, the payoffs to the politician and the public are made.

\section{Agent's Choice}

The problem for a politician that observes a realization equal to $v$ is to

$\operatorname{Max}_{b} \quad I$

The first order condition is

$U^{\prime}-f(t, z) m=0$

The agent equates the marginal utility of consumption to the marginal punishment for exhibiting conspicuous consumption. This punishment is simply the change in the probability the agent is considered corrupt times the punishment implied by these beliefs. Indeed, since the public cannot see what part of the politician's consumption pattern originates in a genuine wealth realization and what part originates in a bribe, it must punish all displays of "excessive" consumption. The agent observes the shock to his wealth and decides what the level of bribes he should take is. Note that this may imply a distortion in consumption (or what in a small abuse of language we can call "negative bribes"). In normal circumstances the agent would certainly consume according to his wealth realization, but his

\footnotetext{
17 The main conclusions of the paper do not change if the timing is altered to allow the politician to observe
} the wealth realization after deciding on the amount of bribes. 
chosen profession (of politician) means that he will have to abstain. ${ }^{18,19}$

Since we are not restricting $F($.$) in any way or form (beyond the standard F(0)=0$ and $F(\infty)=1$ ), in order to ensure that the solution is an interior one we assume that for all the types, there exists a $b<\infty$ such that $U(v+b)-F(t, v+b) m>U(\infty)-m \cdot{ }^{20}$ Note that the conditions on the utility and distribution functions imply that we must have positive bribes at $v=0$. Given the sequence of play, bribes are monotonically decreasing in the realization of income, $v$. A more general result, which is also empirically testable, is the political class exhibits less variance in the consumption of luxuries than the non-political population. In fact, in the extreme example we present the variance is zero (for a given level of wealth). This emphasizes that corruption can be seen as insurance, whereas several models in the literature see it as a gamble. It is also straightforward to see that if $z$ is separated into different goods, each with a different discount rate, there will be more consumption of goods with a high discount rate.

\section{Agent Participation}

The agent's participation constraint is

$$
\int\left[U\left(v+b^{*}\right)-F\left(t, v+b^{*}\right) m\right] f(t, v) d v \geq \int U(v) f(t, v) d v
$$

Note that monitoring consumption has the effect of introducing a form of punishment for people who choose to enter politics that they would otherwise not have. Accordingly, the public has a smaller set of agents from which to elect leaders compared to situations where there is no monitoring consumption. We could not obtain general conditions under which

\footnotetext{
18 The conversation is as follows:

WIFE: Darling, why don't we go to Cancun for the holidays? You know we can afford it this year as my father is paying for it.

POLITICIAN: I know but, what will the people say?

${ }^{19}$ Calling these activities "negative bribes" is less odd than it seems. Since all the public can see is displays of conspicuous consumption, all the distinctions must be made in one plane: we must either have positive and negative bribes or positive and negative consumption. What may be misleading is that a "negative bribe" sounds like the agent is returning some ill-gotten gains to the public. No such thing happens in this model. As we emphasized, the agent simply engages in a sub-optimal pattern of consumption from a personal point of view.

${ }^{20}$ Of course, the first order condition could hold for any number of values of the realization.
} 
the constraint affects differently particular groups (e.g., the rich).

On this account, the model predicts that countries with more access to information about the lifestyle of politicians would tend to have less people interested in entering politics. For example, a practical decision that countries must make is if the statement requiring politicians of disclose their wealth prior to entering politics is going to be made public (such as in the US) or will not (such as in the UK prior to the 1990's). Cultural habits that allow media enquiry would again have the benefit of monitoring consumption but at the cost of reducing the pool of potential politicians. If wealth is not observable, we expect the poor to participate more in politics.

Note that if we extend the setup to consider the possibility of some people being always honest (i.e., people that always set $b=0$ regardless of the circumstances), then under monitoring consumption the honest would experience a distortion in consumption when entering politics. This distortion would always be a reduction in the consumption, and would be larger (in expected terms) for the rich (although it would be smaller in utils). The following lemma summarizes.

Lemma (bad politicians): Agents that are always honest (i.e., who always set $b=0$ ) have fewer incentives to enter politics when there is monitoring consumption.

In our particular setup this honest agents would never enter into politics. Note that dishonest agents also experience a disincentive to entering in to politics. However, some dishonest would still enter because of the opportunity of getting bribes. ${ }^{21}$

\section{The Public's Problem}

Faced with this behavior by the agent, the public must choose a politician with a level of wealth such that expected bribes are a minimum. The public has very little information about the agent's activities, and its objective function is accordingly simple. The public may

\footnotetext{
${ }^{21}$ On the quality of politicians, see Caselli and Morelli (2004); see also Dal Bo and Di Tella (2003) and Levine, Weinschelbaum and Zurita (2006).
} 
have a number of specific objectives in mind, but may be unable to combine them analytically when designing the optimal compensation package. Thus, concentrating on bribe taking is the best it can do. Alternatively, the public may have little information about how much uncertainty is faced by the politician, or the agent's responsibilities could be secret, so there is actually no practical way to do this.

Call $v_{1}(t)$ the level of the wealth realization for which we have $b^{*}\left(v_{1}(t)\right)=0$. Then the probability of the agent being corrupt is

$F\left(t, v_{1}(t)\right)$

The expression $B$ gives the expected bribe that the agent takes, where

$B=\int_{0}^{v_{1}(t)} b^{*}(v(t)) f\left(t, v+b^{*}\right) d v \quad$ s.t. $b^{*} \in \arg \max I$

Thus the problem of the public is to

\section{$\operatorname{Min}_{t} \quad B$}

$$
\begin{aligned}
\text { s.t. } \quad \int\left[U\left(v+b^{*}\right)-F\left(t, v+b^{*}\right) m\right] f(t, v) d v & \geq \int U(v) f(t, v) d v \\
\text { and } \quad b^{*} & \in \arg \max I
\end{aligned}
$$

The first constraint is a participation constraint to ensure the agent is willing to take part in political life and the second is an incentive constraint. Under the assumption that $F(t, z)$ is decreasing in $t$, (for a given level of consumption the rich are punished less, so there is first order stochastic dominance), this leads us to our basic proposition 
Proposition 1: Under 'Monitoring Consumption", the relationship between the agent's wealth and the probability that he/she takes bribes (and with the expected total bribes) is:

1. ambiguous when the public can observe the agent's wealth

2. negative when the public cannot observe the agent's wealth

Proof:

1. The expressions for both $d F\left(t, v_{1}(t)\right) / d t$ and $d B / d t$ cannot be signed.

2. When the public cannot observe wealth $F(t, z)=F(z)$ for all $t$, then the level of consumption $Z^{*}$ would be the same for all types. This means that poorer agents would be getting more bribes (both in size and frequency).

Agent wealth, when is publicly observed, affects bribe taking in our simple model in two ways. First, richer agents tend to take lower bribes because of diminishing marginal utility. Second, a higher level of wealth reduces the punishment for conspicuous consumption, because the latter is less indicative of malfeasance. Proposition 1 shows that, from the point of view of controlling corruption, there is no reason to prefer richer agents when the public can observe the wealth of the politician; while when wealth is not observed the public always does better when it hires a richer agent. In other words, when the rich can hide better the bribes they have obtained they will tend to bribe more, which paired with diminishing marginal utility of income means that the level of agent wealth that minimizes bribes becomes an empirical question.

The first part of proposition 1 may not be very surprising given that we have not imposed strong restrictions on $F($.$) . However, most reasonable assumptions leave this result$ unchanged. This is the case if we assume, for instance, that the variance of income increases with wealth. ${ }^{22}$ This is what we expect to happen if we think that the income generated by a certain amount of wealth is a fixed percentage term of the original amount, such as when we can express returns as plus or minus $\mathrm{x} \%$. It is also possible to think of the $v$ term as inheritance. Then this assumption is equivalent to assuming that wealth is correlated across family members (e.g., rich people have rich aunts). 


\section{Ability and Taxes: Two Important Extensions}

\section{III. a. Ability ${ }^{23}$}

Up to now we have assumed that the public's problem is simply to minimize expected bribes. This simplification obscures the fact that the choice of politician will often depend on other factors, including the perceived ability of the politician. This is important because it is unlikely that, in general, ability and wealth are independently distributed. In this extension we consider politicians who differ in terms of ability and that (at least some form of) ability is valuable to the public.

When ability is observable, the principal's problem is simply extended to take into account the benefits and costs of selecting on ability. Consider two dimensions of ability, $a_{1}$ and $a_{2}$, and a more general welfare function that depends on the amount of bribes and the ability of the politician.

\section{$\operatorname{SW}\left(B, a_{1}, a_{2}\right)$}

To fix ideas, consider the case of ability $a_{1}$ which allows the politician to induce a higher GDP and ability $a_{2}$ that allows the politician to improve the functioning of the state (for example, on how to reduce tax evasion). The archetype of the first case would be US billionaire Bill Gates, who presumably would invent new directions in which to take the country. And the archetype of the second type would be Italy's Silvio Berlusconi, who presumably has such an intimate knowledge of government failure that he would know how to reform it. With a large State it is likely that the gains from type 2 ability are large. Note one complication: when the State is large there are likely large gains from reforming and improving the administration of government, but it is also likely that the distribution of abilities amongst the existing rich in that country is dominated by type 2 ability.

The welfare function $S W($.$) is the reduced form of all these effects. When ability is$ observable, the problem is to

\footnotetext{
22 If we do not assume this we may have that agents that are worth $\$ 10$ may have $\$ 9$ in a bad year and $\$ 11$ in a good year, but an agent worth $\$ 1,000$ is worth $\$ 1,001$ in a good year and $\$ 999$ in a bad one.

${ }^{23}$ We thank a referee for suggesting this extension.
} 


$$
\begin{aligned}
& \operatorname{Max}_{a_{1}, a_{2}, t} \operatorname{SW}\left(B, a_{1}, a_{2}\right) \\
& \text { s.t. } \quad \int\left[U\left(v+b^{*}, a_{1}, a_{2}\right)-F\left(t, a_{1}, a_{2}, v+b^{*}\right) m\right] f\left(t, a_{1}, a_{2}, v\right) d v>\int U\left(v, a_{1}, a_{2}\right) f\left(t, a_{1}, a_{2}, v\right) d v \\
& \text { and } b^{*} \in \arg \max I
\end{aligned}
$$

Note that the distribution of the wealth realization $f\left(t, a_{1}, a_{2}, v\right)$ depends on the pair of abilities, so the optimal level of wealth, $t$, would depend on the ability pair $a_{1}, a_{2}$ chosen. One way to solve this problem is in two steps, in the spirit of Grossman and Hart (1983). First, find the optimal wealth for each pair of abilities $\left(a_{1}, a_{2}\right)$. And then choose the optimal pair of abilities.

When ability is not directly observable, and this is the more interesting case, our calculations need to take into account the fact that we want to choose wealth to minimize bribe taking, but that now wealth might be standing in for ability which may also have value.

One extreme case is that of ability not directly observable but fully independent of wealth. Consider the case of a politician with inherited wealth, and assume (somewhat counterfactually) that the intergenerational transmission correlation of ability within the family is zero. In this case, wealth says very little about ability. Thus, for inherited wealth we are back to our original problem where we only focus on the consequences of wealth for monitoring bribe taking.

In less extreme cases, it would be important to know what type of ability is correlated with wealth. In a country with a small State (low level of government spending over GDP) and where the rich are likely associated with Schumpeterian wealth creation, it is more likely that the wealth of a self made politician is standing in for ability of type $1\left(a_{1}\right)$. This is not certain, so the public will select wealth keeping in mind that different levels of wealth give rise to different distributions of abilities.

A realistic possibility is that we can tell precisely the sector of the economy where the self made person made his or her money. Ability is still not directly observable, but we now know the type of ability most likely to prevail in the sector. Consider the case of a sector 
where firms exclusively sell to the government; or the utilities (where government regulation is key for profitability). Presumably, in these sectors type 2 ability $\left(a_{2}\right)$ prevails, including knowledge of how the State operates (and how abuses can be curved), but (and this is a difference with type 1) it may also mean possessing the ability to understand the bribing technology, or to be less condemning in moral terms of dishonest activities. This second component of type 2 ability may certainly be positively correlated with wealth but have a negative value for society, so the public should use this information when choosing the politician. ${ }^{24}$ This is a new application of the general principle that we present in the paper, namely using observable characteristics to reduce informational costs of controlling corruption. In this case the information available is not only the wealth of the individuals but also the way that they have earned this wealth.

Note, that ability matters even when the public's objective is just to minimize bribe taking (and no considerations of how ability affects social welfare are needed). To see this, consider an able businessperson who creates a trust to manage his/her affairs that is biased towards investment in good projects. This means that the distribution of returns for a given wealth, will be more "skewed to the right" when ability is higher, and a display of conspicuous consumption by the rich (and able) politician is going to be less punished by the public. Formally, $F\left(t, a_{1}, a_{2}, z\right)$ is decreasing in both $a_{1}$ and $a_{2}$, (for a given level of consumption the more able are punished less, so there is first order stochastic dominance). Under bribe minimization as the sole objective of the principal, the following proposition summarizes the effect of ability:

Proposition 2: Under 'Monitoring Consumption", and when the public can observe the agent's wealth, the relationship between the agent's ability and the probability that he/she takes bribes (and with the expected total bribes) is:

1. ambiguous when the public can observe the agent's ability

2. negative when the public cannot observe the agent's ability

\footnotetext{
${ }^{24}$ Some of the reservations to Silvio Berlusconi becoming Prime Minister of Italy in 1994 could be interpreted in this light, as his companies have been accused of bribe paying to reduce the tax burden. Note that such an
} 
Proof:

1. The expressions for $d F\left(t, a_{1}, a_{2}, v_{1}\left(t, a_{1}, a_{2}\right)\right) / d a_{1}, d F\left(t, a_{1}, a_{2}, v_{1}\left(t, a_{1}, a_{2}\right)\right) / d a_{2}, d B / d a_{1}$ and $d B / d a_{2}$ cannot be signed.

2. When the public cannot observe the agent's ability $F\left(t, a_{1}, a_{2}, Z\right)=F(t, z)$ for all $t$, then the level of consumption $z^{*}$ would be the same for all ability types. This means that less able agents would be getting more bribes (both in size and frequency).

The proof is similar to that of proposition 1. In particular part 2 is obtained because consumption will not depend on ability, so those with lower ability will be taking higher bribes.

\section{III. b. Taxes}

Up to now we have not allowed for strategic manipulation of the wealth information that agents make available to the public prior to taking office. In many countries there are provisions whereby agents must make a formal statement of their wealth upon taking a job in the public sector (above a certain job category, usually starting with political appointments). One debate, with which we do not really concern ourselves, is whether such statements of wealth should be made public (e.g., on the web), or made available to anyone in the public after a written request (and usually under strict limitations on how this information can be used by the person requesting the information), or never be made public (but still be used by the authorities in charge of controlling corruption). For the purposes of this paper, we simply note that politicians can jam the process of signal extraction when we monitor consumption that we describe by declaring to be already wealthy when entering public office, presumably at some cost. ${ }^{25}$

It is assumed that this cost is increasing in the income tax rate. Declaring prior wealth may

accusation is directly relevant to our model as the ability to hide firm revenues from the tax authorities is likely related to the ability to hide bribe income from the public

25 This cost does not only include taxes. Indeed, the public may insist in actually observing conspicuous consumption prior to entering politics and the agent may be liquidity constrained (obviously it would be hard to fund such investment projects in the formal finance sector). Then a suboptimal pattern of consumption would result (the politician would drive a Ferrari, yet eat cheap meals at home). 
be costly in terms of tax obligations and this would clearly depend on the tax rates. ${ }^{26}$ To illustrate this effect in a simple way (but see below for a discussion), we note that a higher income tax rate is associated with an improved capacity to monitor agents, so that there is a cost $C$ (.) of taking a bribe of size $b$, which is increasing in the tax rate. A higher income tax rate implies a higher cost of bribes just like any other income. But it also implies that tax agents are more skilled in going over fiscal data, and are able to verify the accuracy of income claims given their experience with deductions and other fiscal data (in brief, we are claiming that there are benefits associated with what is called the fiscal burden by Hall and Rabushka, 1995). Thus, we assume $C^{\prime}>0$ and $C^{\prime \prime}>0$ in

$$
I=U(z)-F(t, z) m-C(b r)
$$

Proposition 3: Under "Monitoring Consumption", when the public can observe the agent's wealth, the relationship between the income tax rate and the probability that an agent (of a given wealth) takes bribes (and with the expected total bribes) is negative.

Proof: It is easy to see that $\frac{d^{2} I}{d b d r}=-C^{\prime \prime}(b r) b r-C^{\prime}(b r)<0$. Note that this not only implies that the local optimum shift to lower bribes, for each level of $v$, but also that for every level bribe higher than $b^{*}$ the reduction of $I$ is higher than for $b^{*}$ which means that the level of bribes would never increase when $r$ increases.

The possible value of proposition 3 is that it shows that even when we maintain the position that no restrictions on the shape of $F($.$) are a priori reasonable, assuming C$ " $>0$, which is realistic, is sufficient to deliver definite predictions regarding the effect on corruption. ${ }^{27}$

\footnotetext{
${ }^{26}$ One could question that agents have such extended planning horizons. However, the experience of Indira Gandhi's chief Minister in the State of Maharashi (Mr Antulay) suggests otherwise. Apparently, he was forced to resign after a high court in Bombay found him guilty of selling cement quotas established by the government. The mechanism used was to ask for "donations" to the trusts he controlled. He "bad established seven trusts, ostensibly for public purposes, but in fact completely controlled by himself. He had obtained income tax exemptions for one trust amounting to U\$110m over the next three years - an indication of the amount he expected generous donors to contribute" (reported in p. 51 of The Economist, January 23, 1982).

27 The results also hold when $C($.$) is linear and even for some concave functions. But note that it is natural to$ assume convexity at the point where extra corruption triggers auditing/punishment.
} 
Of course, one could question the reduced form approach of capturing the economic interactions with the C(.) function in the objective of the agent. Indeed, a full characterization should allow for strategic manipulation of the wealth declaration and a discussion (with hopefully some evidence) on exactly when it is in their careers that politicians typically declare their wealth levels. One extreme assumption is that after elected (under some distribution of types) the agent can present evidence of being a particular type at some cost (e.g., by presenting tax declarations and payments for previous years). The costs of fabrication of such evidence is increasing in the tax rate, exactly as in C(.) above, but now we would need to model the optimal declaration of wealth as well, and the optimal selection of agents when the public knows that such jamming is possible ex post. ${ }^{28}$ This has several complications, but in general it can be shown that the higher tax rate reduces the ability of the agent to be corrupt. Note that this affects the optimal tax structure that countries will choose. Indeed, countries often choose a combination of consumption taxes (like VAT) and personal income taxes. Given that we are pointing towards a possible added benefit of having personal income taxes for the control of political corruption, we expect that the optimal tax structure to be tilted towards personal income taxes (at least with respect to situations where corruption is not a consideration).

Finally, note the importance of incomplete credit markets for our argument to be relevant in some rich countries. In the US, top politicians sometimes become celebrities after leaving office, often writing memoirs for large sums of money. For example, in December 2000, the press reported that Simon \& Schuster agreed to pay Hillary Clinton a reported $\$ 8$ million advance for a memoir of her years as First Lady. ${ }^{29}$ If politicians could get such fees in advance (on the date they start office), electing a poor politician would be similar to electing a rich one since the former would be able to explain any conspicuous consumption with such fee advances by the publishing houses.

\footnotetext{
28 Note that when personal income taxes rise and the capacity of the tax agency improves, it becomes impossible for the agent to use bribe proceeds. In such countries, honesty would not be a product of lack of corruption inclinations but of an inability to use bribe income due to perfect consumption monitoring.

${ }^{29}$ In some cases politicians could increase the value of such documents. See, for example, the case of Pakistani President Prevez Musharraf, who refused to answer a question at a press conference he was hosting during his official State visit to the US (together with US President George W. Bush) citing a contract for his memoirs
} 


\section{Optimal Contract, Same Agent}

In this section we study the role of formal contracts. This has some relevance because improving the salaries of public officials is often emphasized as a way to fight corruption. ${ }^{30}$ The main argument in these debates is the same emphasized by economists, namely that bureaucrats will not engage in risky activities, such as bribe taking, when there is a wage premium to working in the public sector (see, for example, Becker and Stigler (1974), Dickens et al (1989), Besley and McLaren (1993), Mookherjee and Png (1995), inter alia; for the cross country empirical evidence see van Rijckeghem and Weder (2001)). For an analysis of the potential behavioral responses to an exclusive reliance on anti-corruption investigations, see Prendergast (2000).

This policy, however, has problems. For example, for plausible parameter values, wages would have to be extremely high to deter corruption (see, for example, Besley and McLaren, 1993). This is due to a combination of the very low detection probabilities on crimes of bribery and the large amounts of money that can potentially be embezzled by the bureaucrats. In practice, there are very few examples of countries where politicians earn the kind of money that could deter corruption on this logic. ${ }^{31}$ One possible reason is that a policy of high wages for politicians does not carry much favor with the public. The rhetoric suggests this resistance originates in fairness considerations, and it is worth remembering that a stylized fact of bureaucracies, which are more insulated from the public than elected politicians, is the low power of incentive schemes (for discussions and explanations see, for example, Wilson (1989), Tirole (1994), Prendergast (2000) and Besley and Ghatak (2004)).

In this section we point to another practical problem with a formal contract that gives out generous monetary rewards to politicians, namely that it makes monitoring consumption

with Simon \& Schuster as the reason he couldn't go any further into details of his past conversations with members of the Bush Administration.

${ }^{30}$ Although we focus on contracts where agents are remunerated based on the revenues they gather, as applied to some parts of the civil service (notably tax collection), a similar point can be made using flat wages and dismissal as punishment for engaging in corrupt activities.

31 The country that pays highest wages to high level politicians appears to be Singapore, which does not rank well in civic liberties (according to Freedom House). In 1994, for example, it was reported that the annual salary of Goh Chok Tong, Singapore's prime minister, was \$780,000, almost four times that of Bill Clinton. 
difficult. To illustrate, we derive the optimal payment scheme when higher consumption levels provide information about the agent's hidden action and compare it to the contract in the standard case where the agent's subsequent consumption is uninformative. To emphasize the main point on how formal contracts change when consumption is informative, we now assume that agents are homogeneous in terms of type (e.g., wealth, etc). Note that a similar point can be made in the context of a model where payments cannot be state contingent. Indeed, in an efficiency wage model, the observability of consumption leads to lower wages and to more investment by the principal in increasing the detection probability (results available upon request). The intuition is that, when consumption is not observable, the cost of increasing the wage one dollar is just this dollar. But when high wages reduce the informativeness of monitoring consumption there is an additional cost from the reduction in the probability of detection. We start with the standard case where the principal does not observe consumption ex-post, which also serves as the benchmark.

\section{IV.a. No Information in Consumption (benchmark)}

The principal offers the agent a contract. If he accepts, his task is to observe the realization of a variable (say the level of revenue) $\Pi$, which can be high $\Pi_{h}$ (with probability $p_{h}$ ) or low $\Pi_{l}$ (with probability $p_{l}$ ). He then makes a report $\Pi^{a}$. The agent's only discretion occurs when the state is high, as he may report it is low (and keep the difference). The alternative occupation earns him $w_{0}$. The incentive scheme used by the principal is $w\left(\Pi^{a}=\Pi_{h}\right)=w_{h}$ and $w\left(\Pi^{a}=\Pi_{l}\right)=w_{l}$. When the principal does not observe consumption, the agent will report the truth when $U\left(w_{h}\right) \geq U\left(w_{l}+\Pi_{h}-\Pi_{l}\right)$. And will agree to participate when $p_{h} U\left(w_{h}\right)+p_{l} U\left(w_{l}\right) \geq U\left(w_{0}\right)$.

Denote $\psi($.$) the inverse of U$. Since $U$ is an increasing and concave function, it is easy to see that both constraints hold with equality, so the optimal incentive contract satisfies

Starting annual salaries for cabinet ministers were $\$ 419,285$ (over three times that of UK prime minister at the time). They were raised 25\% in 1995. Reported in The Economist, November 26th, 1994. 


$$
\begin{aligned}
w_{h}-w_{l} & =\Pi_{h}-\Pi_{l} \\
w_{l} & =\psi\left(\frac{U\left(w_{0}\right)-p_{h} U\left(w_{h}\right)}{p_{l}}\right)
\end{aligned}
$$

\section{IV.b. Observing Consumption}

To model the fact that consumption is informative, we assume that there is some noise in the agent's level of legal income. For example, the agent invests his wage and bribes and earns a random return. ${ }^{32}$ This is given by

\section{$\phi \times$ income}

where $\phi$ is the realization of random variable $\Phi$. To emphasize this, we alter the timing (with respect to the one used in section III) and assume that the agent makes his decision to become corrupt prior to observing the realization of this random variable. A second difference is that we now assume that the agent must consume his total income. Thus, he cannot hide the bribe and must consume it under the eyes of the public. Neither of these assumptions is essential but help simplify the exposition. The probability that the agent has taken bribes is derived given the agent's legal income and observed consumption level, and he is punished for such suspicions with a punishment $m$. Thus, total punishment is given by

\section{F(legal income, consumption $) \times m$}

where the first term is the probability that $\Phi \leq \frac{\text { consumption }}{\text { legal income }}$. The agent's utility is

$U(\phi($ total income $))-F($ legal income,$\phi$ total income $) m$

Thus, the timing is 


\begin{tabular}{|c|c|c|c|c|c|}
\hline $\begin{array}{l}\text { principal } \\
\text { chooses } \\
\text { payment } \\
\text { scheme }\end{array}$ & $\begin{array}{c}\text { nature chooses } \\
\text { output }\end{array}$ & $\begin{array}{l}\text { agent chooses } \\
\text { action } \\
\text { wages are paid }\end{array}$ & $\begin{array}{c}\text { wage and bribes } \\
\text { are invested }\end{array}$ & $\begin{array}{l}\text { nature chooses } \\
\text { return (not } \\
\text { observable by } \\
\text { the principal) }\end{array}$ & $\begin{array}{l}\text { payoffs are } \\
\text { made }\end{array}$ \\
\hline
\end{tabular}

\section{Agent's Choice}

When the agent observes $\Pi_{h}$, the incentive compatibility constraint is

$$
\int\left[U\left(\phi w_{h}\right)-F\left(w_{h}, \phi w_{h}\right) m\right] d \phi \geq \int\left[U\left(\phi\left(w_{l}+\Pi_{h}-\Pi_{l}\right)\right)-F\left(w_{l}, \phi\left(w_{l}+\Pi_{h}-\Pi_{l}\right)\right) m\right] d \phi
$$

Comparing the optimal payment scheme when we can monitor consumption versus when we cannot, we obtain the following proposition,

Proposition 4: The optimal contract when there is monitoring consumption has lower power than the optimal contract in the benchmark case when there is no consumption monitoring.

Proof: We can rewrite the incentive compatibility constraint as follows

$$
\int\left[U\left(\phi w_{h}\right)-U\left(\phi\left(w_{l}+\Pi_{h}-\Pi_{l}\right)\right)\right] d \phi \geq \int m\left[F\left(w_{h}, \phi w_{h}\right)-F\left(w_{l}, \phi\left(w_{l}+\Pi_{h}-\Pi_{l}\right)\right)\right] d \phi
$$

When this constraint is not binding, the principal gives the agent a constant wage that minimizes expected costs (as the agent is risk averse and punishment through $m$ is enough to induce truthful reports). When it holds with equality, the right hand side can be written as

$$
\int m\left[\operatorname{Pr}\left(\Phi \leq \phi \frac{w_{h}}{w_{h}}\right)-\operatorname{Pr}\left(\Phi \leq \phi \frac{w_{l}+\Pi_{h}-\Pi_{l}}{w_{l}}\right)\right] d \phi
$$

\footnotetext{
32 Results do not change if the agent is not allowed to invest the bribe income.
} 
which is less than zero, because $\phi \frac{w_{h}}{w_{h}}=\phi$ is smaller than $\phi \frac{w_{l}+\Pi_{h}-\Pi_{l}}{w_{l}}$ and the probability is an increasing function. (The reason is that $\Phi$, the realization of the uncertainty about the agent's legal income, is independent of the agent's behavior, and because for any realization, the public's punishment is higher when the agent announces $\Pi_{l}$ ). The left hand side is also less than zero and $w_{h}-w_{l}<\Pi_{h}-\Pi_{l}$.

In other words, when there is monitoring consumption the optimal incentive contract is characterized by a difference in wages that is smaller than $\left(\Pi_{h}-\Pi_{l}\right)$, which is the difference in the standard case when consumption is not monitored.

Finally, it is worth noting that both our applications point out to a distinction between legal and illegal income. A large literature in economics (crime, principal agent models, etc) assumes the existence of a "cost" from misbehaving (relative to the norms of society or from what the principal expects). ${ }^{33}$ We emphasize this by showing that illegal income is less valuable than legal income. To see this, and following the notation of the model for state contingent contracts for simplicity, we note that the utility of the agent when he reports the state as low when it is in fact high is

$U\left(\phi\left(w_{l}+\Pi_{h}-\Pi_{l}\right)\right)-F\left(w_{l}, \phi\left(w_{l}+\Pi_{h}-\Pi_{l}\right)\right) m$

This can be rewritten as follows

$$
\begin{aligned}
& U\left(\phi\left(w_{l}+\Pi_{h}-\Pi_{l}\right)\right)-F\left(w_{l}+\Pi_{h}-\Pi_{l}, \phi\left(w_{l}+\Pi_{h}-\Pi_{l}\right)\right) m- \\
& \quad\left[F\left(w_{l}, \phi\left(w_{l}+\Pi_{h}-\Pi_{l}\right)\right)-F\left(w_{l}+\Pi_{h}-\Pi_{l}, \phi\left(w_{l}+\Pi_{h}-\Pi_{l}\right)\right)\right] m
\end{aligned}
$$

\footnotetext{
33 In some corruption applications the payoff from dishonesty typically includes a bribe but also a negative term often labeled a "moral cost" (see, Rose-Ackerman, 1975). The connection between morality and incentives, however, is unappealing because sometimes incentives are not aligned properly for very large groups of people and it would be strange to claim that their actions are not moral. Put differently, even if the incentives in Argentina and Sweden were such that a majority (minority) of people in Argentina (Sweden) are corrupt, few would seriously claim that there are more good people in Sweden.
} 
The first two terms are the utility units that the agent would get for a given level of income if this had all been earned legally. The third term (in squared brackets) is the difference in punishment because the income coming from illegal sources appears suspicious. Note that since $F($.$) is decreasing in the first argument, the term in squared brackets is positive, which$ proves our claim.

Note that legal income increases the agent's utility through two channels. First, we have the standard effect operating through higher consumption. Second, higher income reduces the popularity penalty because a given level of consumption is less likely to originate in corruption by the agent.

\section{Conclusions}

There are numerous examples of cases where corruption is discovered because an agent was observed to enjoy an unexpectedly high standard of living, or, more precisely, a level of consumption that could not be easily explained given the information available about the agent's level of wealth. This suggests that there are potential benefits from designing incentive contracts and choosing agent type with the idea of using the information that is obtained from monitoring consumption.

There are (at least) two basic effects of hiring agents on a high income arising either because of high personal income or because of a generous compensation. On the one hand, bribe offers are less tempting to the rich due to diminishing marginal utility. On the other, high levels of income also make an observed level of consumption less informative about any bribes the agent might have taken. We discuss the general incentive problem of choosing agents and monitoring consumption, as well as two applications to settings where corruption is common. The first is a setting where informal incentive contracts are prevalent, such as the control of a high level politician by the public. Our basic result is that when there is consumption monitoring and wealth is observed there is a tendency to choose poorer politicians to reduce corruption. It can also be shown that the political class is expected to exhibit lower variance in consumption; that there is higher value in monitoring the consumption of goods with high discount rates (such as education or health care); and that 
the gains from monitoring consumption and selecting agents according to wealth depend on the level of taxes in the country as well as on the relationship between wealth and ability.

The second setting concerns the control of potentially corrupt bureaucrats through formal incentive contracts. In this case, paying generous wages has problems beyond the fiscal cost because it lowers the value of monitoring consumption. We show that, when state contingent contracts are used, the power of incentive schemes is lower. This is one possible explanation for why we often observe low powered incentive contracts in bureaucracies. The argument can be applied to wages that are not state contingent, such as efficiency wages. In this case monitoring consumption introduces a tendency for lower wages (and higher investment in detection), something that is one way of explaining popular resistance to pay politicians very high wages. Finally, our analysis provides one way of to assess the value of illegal income to a corrupt agent. 


\section{$\underline{\text { References }}$}

Becker, Gary and George Stigler (1974) "Law Enforcement, Malfeasance, and the Compensation of Enforcers", Journal of Legal Studies, vol.3, 1-18.

Besley, Timothy and John McLaren (1993) "Taxes and Bribery: The Role of Wage Incentives”, Economic Journal, 103, 119-41.

Besley, Tim and Maitreesh Ghatak (2004) "Competition and Incentives with Motivated Agents", mimeo LSE.

Candelaresi, Cledis (2006) "El plasma que compró un moroso y terminó en las arcas de Montoya", newspaper article of 29 June in the newspaper Pagina12.

Caselli, Francesco and Massimo Morelli (2004) "Bad Politicians", Journal of Public Economics, 88, 3-4, 759-82.)

Colombo, Gherardo (1997) "Remarks on Controlling Corruption", mimeo presented at the 8th International Anti-Corruption Conference in Lima, Peru.

Dal Bo, Ernesto and Rafael Di Tella (2003) "Capture by Threat", Journal of Political Economy, vol. 111, no. 5, pp. 1123-54.

Dickens, William, Lawrence Katz, Kevin Lang and Lawrence Summers (1989) "Employee Crime and the Monitoring Puzzle", Journal of Labor Economics, 7, 3, 331-47.

Gibbons, Robert and Michael Waldman (1999) "Careers in organizations: theory and evidence," in the Handbook of Labor Economics, Vol. 3B, Orley Ashenfelter and David Card (eds) Amsterdam : Elsevier Science, 2384-420.

Grossman, Sanford and Oliver Hart (1983) "An Analysis of the Principal-Agent Problem," Econometrica, 51, 1, 7-45.

Hall, Robert and Alvin Rabushka (1995) The Flat Tax, Hoover Press, $2^{\text {nd }}$ edition.

Holmstrom, Bengt (1979) "Moral Hazard and Observability" Bell Journal of Economics, Spring, 10(1), 74-9.

Laffont, Jean Jacques and Tcheche N'Guessan (1999): "Competition and Corruption in an agency relationship”, Journal of Development Economics, vol. 60, pp. 271-95.

Laffont, Jean-Jaques and Jean Tirole (1993) The Theory of Incentives in Procurement and Regulation, Boston: MIT Press.

Levine, David K., Federico Weinschelbaum and Felipe Zurita (2006) "The Brother in Law Effect", mimeo UCLA.

Mookherjee, Dilip and Ivan Png (1992) "Monitoring vis-à-vis Investigation in Enforcement of Law," American Economic Review, 82, 3, 399-415.

Mookherjee, Dilip and Ivan Png (1995) "Corruptible Law Enforcers: How Should they be Compensated”, Economic Journal, 104, 145-59.

Prendergast, Canice, (1999) "The Provision of Incentives in Firms", Journal of Economic Literature, 37, 7-63.

Prendergast, Canice (2000) "Investigating Corruption" mimeo University of Chicago.

Rasmusen, Eric (1992) “An Income Satiation Model of Efficiency Wages”, Economic Inquiry, July, 30, 467-78.

Rogoff, Kenneth (1985) "The Optimal Degree of Commitment to an Intermediate Monetary Target”, Quarterly Journal of Economics, C (November): 1169-90.

Rose-Ackerman, Susan (1975) "The Economics of Corruption", Journal of Public Economics, 4, (February) 187-203.

Rotemberg, Julio and Garth Saloner (2000) "Visionaries, Managers, and Strategic Direction," Rand Journal of Economics, 31, Winter, 693-716.

Schelling, Thomas (1960) The Strategy of Conflict, Harvard University Press 
Shavell, Steven (1979) "Risk Sharing and Incentives in the Principal and Agent Relationship," Bell Journal of Economics, Spring 10 (1), pp. 55-73.

Tirole, Jean (1994) "The Internal Organization of Government", Oxford Economic Papers, 46, 1-29.

Van Rijckeghem, Caroline and Beatrice Weder (2001) "Bureaucratic corruption and the rate of temptation: do wages in the civil service affect corruption and by how much?" Journal of Development Economics 65, 307-31.

Vickers, John (1985) "Delegation and the Theory of the Firm", Economic Journal, 95, 138-47.

Walsh, Carl E. (1995) "Optimal Contracts for Central Bankers", American Economic Review, Vol. 85, No. 1, pp. 150-67

Wilson, James (1989) Bureaucracy: What Government Agencies Do and Why They Do It, Basic Books.

World Bank (1997) World Development Report: The State in a Changing World, New York: Oxford University Press. 